originalni

naučni rad
Primljen: 06.05.2019. Prihvaćen: 21.12 .2019

\section{Valutni odbor, monetarna regulacija i makroprudenciona regulacija u Bosni i Hercegovini}

Dragan Jović, Centralna banka Bosne i Hercegovine, Glavna banka Republike Srpske

email: draganjovic@blic.net

Prevod Sažetak: Ovo istraživanje predstavlja efekte primjene diskrecionih i automatobezbedio autor skih instrumenata u četiri slučaja monetarne i makroprudencione regulacije u Bosni i Hercegovini. Efektivnost politike valutnog odbora se povećava ako se njegova ortodoksija smanjuje. Izmjerili smo novčane uslove prije i poslije globalne krize. Monetarni uslovi su se poboljšavali od drugog kvartala 2014. godine. Izolovani su efekti negativne naknade na višak rezervi na primarnom tržištu javnog duga BiH. Procjenili smo, takođe, efekte diferencirane stope obavezne rezerve na ročnu strukturu pasive bankarskog sektora u Bosni i Hercegovini. Na kraju, testiran je odnos između obavezne rezerve kao instrumenta monetarnog regulisanja i rasta kredita. Istraživanje je pokazalo da Centralna banka Bosne i Hercegovine može uticati na neke operativne varijable/ indikatore monetarne politike. Svi nalazi pokazuju da Centralna banka Bosne i Hercegovine nije "obična mjenjačnica“ i da zaista može voditi autonomnu i diskrecionu monetarnu politiku.

Ključne reči: monetarna politika, valutni odbor, obavezna rezerva, indeks monetarnih kretanja, negativna naknada.

JEL: E42, E52, E58, G28 


\section{Uvod}

Rasprostranjen način razmišljanja o bh valutnom odboru jeste da je Centralna banka Bosne i Hercegovine (CBBiH) "obična mjenjačnica”, tj. da ne vodi autonomnu i diskrecionu monetarnu politiku. Ova vrsta takozvanog "glavnog toka monetarnog mišljenja" o bh valutnom odboru je glavna motivacija za istraživanje koje želimo da predstavimo. Naša glavna hipoteza je da CBBiH provodi i može da provodi monetarnu politiku, iako je devizni kurs fiksan, iako bh referentna kamatna stopa i emisiona banka kao ustanova posljednjeg utočišta (eng. lender of last resort) ne postoje i iako postoji automatska konverzija bh (BAM) u rezervnu valutu (EUR). Da bismo dokazali ovu hipotezu, ispitaćemo efekte nekoliko instrumenata monetarne politike i makroprudencione politike u monetarnom režimu Bosne i Hercegovine. Kroz analizu monetarnih uslova, obavezne rezerve, diferencirane stope obavezne rezerve i naknade na višak iznad obavezne rezerve, želimo dokazati da postoje efekti domaće monetarne i makroprudencione regulacije i da se ona sprovodi korištenjem diskrecionih, pa čak i automatskih instrumenta monetarne i makroprudencione politike. Autonomija monetarne politike je u istraživanju definisana kao sposobnost uticaja na kratkoročne prinose i na kreditni rast.

U prvom dijelu istraživanja dajemo pregled literature, a nakon nakon toga slijedi dio o podacima i metodologiji. Centralni dio istraživanja ima četiri sekcije: a) indeks monetarnih uslova, b) negativna naknada na višak iznad obavezne rezerve, c) diferencirana stopa obavezne rezerve i d) stopa obavezne rezerve. Na kraju istraživanja nalaze se zaključci i reference.

\section{Pregled literature}

Ne postoji jedinstven stav o stepenu autonomije monetarne politike u uslovima fiksnog deviznog kursa, pa samim tim ni u uslovima novčanog odbora. Pojedini autori smatraju da je fiksni devizni kurs dobra opcija čak i u uslovima visokog stepena valutne supstitucije i endogenih šokova (Calvo, 1999). Na drugoj strani su autori (Obstfeld i Rogoff, 1995) koji, analizirajući krizu Evropskog mehanizma deviznih kurseva tokom 1992.godine, kao i Meksičku krizu (19941995) zaključuju da fiksni devizni kurs vodi gubljenju kontrole nad ponudom novca. Princip „nemogućeg trojstva“ poručuje da je samostalna monetarna politika nemoguća u režimu fiksnog deviznog kursa i u odsustvu kontrole kretanja kapitala (Fleming, 1963), a čak se i režimu varijabilnog deviznog kursa osporava autonomna monetarna politika u uslovima velike mobilnosti kapitala (Rey,2015). Postoje i stavovi da se kvalitetna monetarna politika zasniva na trojstvu varijabilnog deviznog kursa, inflacionog targetiranja i monetranog pravila (Taylor, 2000), čime se apsolutno odbacuje režim fiksnog deviznog kursa, pa i novčanog odbora. U nekim istraživanjima izvršena je ekonometrijska verifikacija hipoteze da je stepen autonomije monetarne politike (mjereno sposobnošću uticaja na kratkoročne kamatne stope) veći u režimu varijabilnog nego u režimu fiksnog deviznog kursa (Shaumbaugh, 2002).

Indeks monetranih uslova (MCl), kao mjera monetarnih uslova, koristi se od kraja prošlog vijeka, tj. od početka devedesetih godina. Tumačenje $\mathrm{MCl}$ je 
diskutovano u radovima koje su napisali Neil i saradnici (2006) i Osborne i Holton (2010). MCI je razvijen za Hong Kong (HKMA, Kvartalni bilten 11/2010), a o pitanjima vezanim za $\mathrm{MCl}$ je diskutovano i u zoni evra (ECB, Mjesečni bilten, 2002). Neke od zemalja u neposrednom bh okruženju poput Hrvatske, (Benazić, 2012) i Albanije (Kodra, 2010) razvile su MCl. Glavni zaključak o MCI jeste da postoje različite metodologije za njegovo izračunavanje, a njegova vrijednost se mnogo razlikuje u zavisnosti od korištene metodologije. U domaćoj literaturi postoji samo jedna referenca o negativnim naknadama na višak rezervi (Jović, 2017) u kojoj se ukazuje na njen uticaj na prinose na primarnom tržištu javnog duga bh entiteta. Nismo našli niti jedno istraživanje o diferenciranoj stopi obavezne rezerve, ili obavezne rezerve u $\mathrm{BiH}$. Sa druge strane, stopa obavezne rezerve se intezivno analizira u inostranoj literaturi, što nije slučaj sa uticajem diferencirane stope obavezne rezerve (DRRR) na ročnu strukturu i na obaveze bankarskog sektora. Glavno istraživanje u ovoj oblasti (IMF, 2011 i IMF, 2013) pokazalo je da stopa obavezne rezerve (RRR) smanjuje procikličnost bankarskih kredita i da RRR može smanjiti portfolio investicije u zemljama sa fleksibilnim deviznim kursom. Marginalna obavezna rezerva za devizne obaveze banake uz korištenje kapitalnog zahteva usporava rast cijena nekretnina na evropskim tržištima u nastajanju (Vandenbussche i saradnici, 2012), dok RRR na kratkoročne obaveze smanjuje rast kredita.

\section{Podaci i metodologija}

Procjenili smo efekte bh monetarne i makroprudencione regulacije na četiri načina. Prvi način je merenje monetarnih uslova, tj. izgradnja indeksa novčanog stanja $(\mathrm{MCl})$. Ako su monetarni uslovi u BiH poboljšani nakon izbijanja globalne krize, onda je monetarna politika bila efikasna. Drugi način merenja efekata monetarne i makroprudencione regulacije u BiH je procjena efekata negativne naknade na višak rezervi.

Treći i četvrti način mjerenja su efekti diferencirane stope obavezne rezerve i efekata stope obavezne rezerve na dugoročne depozite i stopu rasta kredita.

Indeks monetarnog stanja $(\mathrm{MCl})$ je izumljen u Kanadi krajem dvadesetog vjeka (tokom devedesetih godina). $U$ originalnoj formi, predstavljen je kao:

$M C I=-\left(\alpha\left(i r-i r_{b}\right)+\beta\left(R E E R-R E E R_{b}\right) 100\right)$

gdje su: ir i $i r_{b}$ aktivna domaća bankarska kamatna stopa i aktivna domaća bankarska kamatna stopa u baznoj godini, a REER i REER $R_{b}$ logaritam realnog efektivnog deviznog kursa i logaritam realnog efektivnog deviznog kursa u baznoj godini. Primijenili smo isti oblik $M C l$ u našem istraživanju. Za baznu godinu koristili smo 2010. godinu, tj. prosjek za domaću kamatnu stopu i REER za ovu godinu, jer se domaći indeks industrijske proizvodnje računa za istu baznu godinu. Neke karakteristike konstrukcije $\mathrm{MCl}$ moraju biti detaljnije objašnjene. Znak minus ispred jednačine određen je zbog uticaja domaće kamatne stope i realnog efektivnog kursa na monetarne uslove i zbog jednostavnosti tumačenja. Ako kamatne stope i REER porastu, takva promjena je negativna i obrnuto. Povećanje $\mathrm{MCl}$ predstavlja poboljšanje monetarnih uslova, dok smanjenje $\mathrm{MCl}$ predstavlja pogoršanje novčanih uslova. Drugi dio 
jednačine (tj. razlika u REER) se množi sa 100 da bi se došlo do promjene REER u procentima. Postoji mnogo načina procjene $\mathrm{MCl}$, a mi smo izabrali originalni i najjednostavniji. Koeficijenti $\alpha$ i $\beta$ su izvedeni iz modela predstavljenog kao;

$I I P_{g r}=c(1)+c(2) * I I P_{g r}(-1)+c(3) * I R(-1)+c(4) * R^{2} E R_{g r}(-1)$

gdje su $I I P_{g r}$ stopa rasta industrijske proizvodnje, c(3) je $\alpha$, a c(4) je $\beta, I R$ domaća kamatna stopa (aktivna kamatna stopa bh banaka), a REER je realni efektivni devizni kurs.

$\mathrm{U}$ martu 2016. godine, prvi put u monetarnoj istoriji $\mathrm{BiH}$, uvedena je negativna naknada na višak rezervi. Odluka je stupila na snagu tri meseca kasnije. $\mathrm{CBBiH}$ je povezala svoju naknadu na višak sredstava iznad obavezne rezerve sa kamatnom stopom ECB. U vrijeme kada je donijeta odluka ova stopa ECB je negativna - $0,4 \%$. Izmjerili smo efekte ove promjene pomoću Wilcoxon Mann - Whitney testa, tj. testa sume rangova. Ovaj test pokušava da utvrdi da li postoji razlika između opservacija izloženih različitim tretmanima. U našem slučaju, tretman je negativna naknada na višak rezervi tj. odsustvo negativne naknade na višak rezervi. Primjetili smo efekte naknada na primarnom tržištu trezorskih zapisa i obveznica bh entiteta (Republika Srpska/RS i Federacija Bosne i Hercegovine/FBiH). Naša pretpostavka je da mora postojati razlika u prinosima na primarnom tržištu prije i nakon uvođenja negativne naknade. Sa testom sume rangova, neparametarskim testom (Žižić et al., 1992. p. 351) provjerili smo ovu tezu. Nulta hipoteza u ovom testu je da je stopa prinosa do dospjeća jednaka prije i nakon uvođenja negativne naknade.

Od 1. januara 2009. do 1. jula 2016. godine monetarni režim u BiH posluje sa $D R R R$, tj. sa nižom obaveznom rezervom na dugoročne depozite i višom obaveznom rezervom na kratkoročne depozite (Tabela 1). Na početku ove vrste monetarnog režima, kao vrste makroprudencione regulacije, $R R R$ je iznosila $14 \%$ na kratkoročne depozite i 10\% na dugoročne depozite.

Tabela 1: DRRR u Bosni i Hercegovini

\begin{tabular}{|c|c|c|c|c|}
\hline & $\begin{array}{c}\text { 1. januar } \\
2009 .\end{array}$ & $\begin{array}{c}1 . \text { maj } \\
2009 .\end{array}$ & $\begin{array}{c}1 . \text { februar } \\
2011 .\end{array}$ & $\begin{array}{c}\text { 1. juli } \\
2016 .\end{array}$ \\
\hline $\begin{array}{c}R R R \text { na obaveze sa } \\
\text { dospjećem } \\
\text { ispod godinu dana }\end{array}$ & $14 \%$ & $14 \%$ & $10 \%$ & $10 \%$ \\
\hline $\begin{array}{c}R R R \text { na obaveze sa } \\
\text { dospjećem } \\
\text { iznad godinu dana }\end{array}$ & $10 \%$ & $7 \%$ & $7 \%$ & $10 \%$ \\
\hline
\end{tabular}

Izvor: $\mathrm{CBBiH}$.

Koristili smo višestruki regresioni model (parametri u modelima su ocijenjeni metodom najmanjih kvadrata) da bi se pronašla veza između $D D D R$ i stope rasta dugoročnih depozita. $U$ tu svrhu smo uveli vještačku varijablu za $D D D R$; vrijednost 1 u periodu 01/2009-06/2016, a izvan toga perioda 0. Ostali regresori bili su EURIBOR i domaće varijable; neperformansni krediti, stopa rasta $B D P$, stopa rasta kratkoročnih depozita i depozitni multiplikator (inverzna vrijednost stope obavezne rezerve). 
Da bismo testirali efekte $R R R$ na rast kredita, koristili smo takođe višestruki linearni regresioni model. Pored $R R R$ u model smo uveli i puno regresora i kontrolnih varijabli: kreditni rast (sa vremenski pomakom), povrat na kapital bh bankarskog sektora, stopa rasta industrijske proizvodnje, stopa rasta $B D P$, stopa rasta depozita, $C P I$, odnos kredita i aktive $(L A)$ i vještačku varijablu za krizu (od povlačenja strane pasive iz bankarskog sektora BiH (03/2009) pa do 06/2016. godine vrijednost ove varijable je 1) i pokretni prosjek. Dijagnostika za sve modele uključuje provjeru autokorelacije (Durbin-Watson test, LM test, $Q$ statistika), normalnost rasporeda reziduala (Jarque-Berra test) i test homoskedastičnosti (test Breusch-Pagan-Godfrey). Broj stepeni slobode je određen kao $n$-k, gdje je $n$ broj opservacija, a $k$ broj parametera (uključujući konstantu, ako postoji) koji se ocjenjuju.

Da bi olakšali izlaganje rezultata istraživanja, koristili smo mnoštvo skraćenica (akronimi su izvedeni iz naziva na engleskom, a ne na srpskom jeziku).

Tabela 2: Popis korištenih skraćenica i izvori vremenskih serija

\begin{tabular}{|c|c|c|c|}
\hline BR. & Skraćenice & Naziv na srpskom & $\begin{array}{c}\text { Izvori } \\
\text { vremenskih } \\
\text { serija }\end{array}$ \\
\hline 1. & $\mathrm{BSBH}$ & bankarski sektor BiH & - \\
\hline 2. & BSFBH & bankarski sektor FBiH & - \\
\hline 3. & $\mathrm{CBBH}$ & Centralna banka BiH & - \\
\hline 4. & $\mathrm{CPI}$ & indeks potrošačkih cijena & BHAS \\
\hline 5. & DGR & stopa rasta depozita & $\mathrm{CBBiH}$ \\
\hline 6. & DUM_CRISIS & vještačka varijabla za krizu & - \\
\hline 7. & DUM_MPR & vještačka varijabla za makroprudencionu regulaciju & - \\
\hline 8. & DRRR & diferencirana stopa obavezne rezerve & $\mathrm{CBBiH}$ \\
\hline 9. & DW & Durbin-Votsonov test & - \\
\hline 10. & EURIBOR & dvanaestomjesečni EURIBOR & ECB \\
\hline 11. & GDP & bruto domaći proizvod & BHAS \\
\hline 12. & GDP_GR & stopa rasta bruto domaćeg proizvoda & BHAS \\
\hline 13. & IIP & indeks industrijske proizvodnje & BHAS \\
\hline 14. & IP_GR & stopa rasta industrijske proizvodnje & BHAS \\
\hline 15. & IMF & Međunarodni monetarni fond & - \\
\hline 16. & LA & udjel kredita u aktivi & $\mathrm{CBBiH}$ \\
\hline 17. & LGR & stopa kreditnog rasta & $\mathrm{CBBiH}$ \\
\hline 18. & LR & bh aktivna kamatna stopa & ABRS i FBA \\
\hline 19. & $\mathrm{MCl}$ & indeks monetarnih uslova & - \\
\hline 20. & NPL & neperformansni krediti & $\mathrm{CBBiH}$ \\
\hline 21. & REER & realni efektivni devizni kurs & $\mathrm{CBBiH}$ \\
\hline 22. & REER_GR & stopa rasta realnog efektivnog deviznog kursa & $\mathrm{CBBiH}$ \\
\hline 23. & ROAE & povrat na prosječan dionički kapital & $\mathrm{CBBiH}$ \\
\hline 24. & $\mathrm{ROE}$ & povrat na dionički kapital & $\mathrm{CBBiH}$ \\
\hline 25. & RRR & stopa obavezne rezerve & $\mathrm{CBBiH}$ \\
\hline 26. & STD_GR & stopa rasta kratkoročnih depozita & $\mathrm{CBBiH}$ \\
\hline 27. & TB & trezorski zapisi & - \\
\hline
\end{tabular}




\section{Rezultati i diskusija}

\section{Indeks monetarnih kretanja (MCI)}

Kreirani regresioni model je vrlo dobra reprezentacija odnosa između industrijske proizvodnje i kamatnih stopa/realnog efektivnog deviznog kursa (Tabela 3). Skoro svi koeficijenti su statistički značajni na nivou od 1\% i ispod. Vrjednosti koeficijenata uz regresor $L R$ i $R E E R \_G R$ su -1,66 i - 2,12. Ovi koeficijenti, kao što je i očekivano, imaju negativan znak, odnosno rast u $L R \mathrm{i}$ $R E E R \_G R$ smanjuje vrijednost rasta industrijske proizvodnje. Prema dijagnostici modeli su nepristrasne ocijene vrijednosti parametara. $U$ modelu nema autokorelacije niti heteroskedastičnosti. Distribucija reziduala je normalna, a srednja vrijednost reziduala je nula.

Tabela 3: Regresioni model, zavisna varijabla - stopa rasta industrijske proizvodnje

\begin{tabular}{|l|l|l|l|l|}
\hline & \multicolumn{1}{|c|}{ Koeficijenti } & \multicolumn{1}{c|}{ S.G. } & \multicolumn{1}{c|}{ t } \\
\hline C & 8,16 & 2,18 & 3,75 & 0,0006 \\
\hline IIP_GR-(-1) & 0,33 & 0,13 & 2,59 & 0,0141 \\
\hline LR & $-1,66$ & 0,43 & $-3,90$ & 0,0004 \\
\hline REER_GR & $-2,12$ & 0,68 & -313 & 0,0035 \\
\hline & & & & \\
\hline$R^{2}$ & 0,45 & & & \\
\hline Prilagođeni R & 0,38 & & & \\
\hline DW statistika & 1,99 & & & \\
\hline $\begin{array}{l}\text { Q- statistika } \\
\text { (prvi ilidrugi lag) }\end{array}$ & $0,0131(0,909)$ & & & \\
\hline $\begin{array}{l}\text { Statistika Jarque-Berra } \\
\text { test }\end{array}$ & $2,71(0,26)$ & & & \\
\hline $\begin{array}{l}\text { Srednja vrijednost } \\
\text { reziduala }\end{array}$ & 0 & & & \\
\hline $\begin{array}{l}\text { Breusch-Pagan-Godfrey } \\
\text { test }\end{array}$ & $\begin{array}{l}6,07 \\
(0,108)\end{array}$ & & & \\
\hline Broj stepeni slobode & 37 & & & \\
\hline Vremenski period & $2007 Q 2-2017 Q 2$ & & & \\
\hline
\end{tabular}

Izvor:Autor

Model je osnova za konstrukciju $\mathrm{MCl}$. Kada smo ga primjenili dobili smo sljedeću formulu za bh $\mathrm{MCl}$ indeks,

$M C I=-\left(-1.66\left(i r-i r_{b}\right)-2.12\left(\right.\right.$ REER $\left.\left.-R E E R_{b}\right) 100\right)$ ili

$M C I=-\left(\frac{1.66}{2.12}\left(i r-i r_{b}\right)+\left(R E E R-R E E R_{b}\right) 100\right)$

MCI pokazuje da se monetarni uslovi poboljšavaju od Q2 2014 (Grafikon 1), u poređenju sa izabranim baznim periodom (Ø Q32007 - Q42008). Postoji velika korelacija u kretanju REER i $\mathrm{MCl}$, jer je REER glavna determinanta $\mathrm{MCl}$ (Grafikon 1). Izračunati MCl odnos 0,78 $(1,66 / 2,12)$ je veoma nizak u poređenju sa drugim istraživanjima, doprinos REER izmjeni monetarnih uslova je zna- 
čajno veći u slučaju Bosne i Hercegovine. Ova činjenica bi se mogla objasniti odsustvom referentne kamatne stope bh emisione banke. Doprinos REER poboljšanju monetarnih uslova je veći nego doprinos kamatnih stopa zbog većeg smanjenja (depresijacije) u REER nego u kamatnim stopama u odnosu na bazni period. Kanal deviznog kursa u BiH je važniji i intenzivniji nego kanal kamatnih stopa. Kretanje REER je potpuno van kontrole domaće monetarne politike, a to znači da na monetarne uslove u BiH utiču automatski faktori, a ne diskrecioni instrumenti monetarne politike.

\section{Grafikon 1: Indeks monetarne politike u Bosni i Hercegovini}

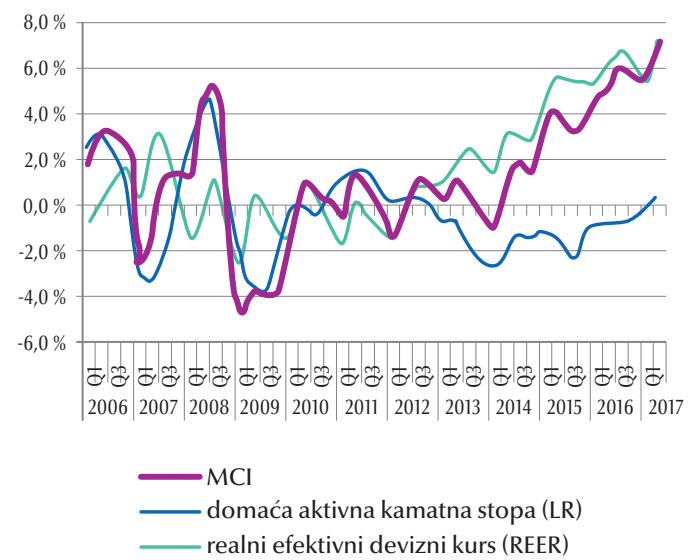

Izvor: Autor

U 2016. i u prva dva kvartala 2017. godine $\mathrm{MCl}$ je mnogo veći od baznog $\mathrm{MCl}$ (veći je za oko 6\%). Ali do zaključka da su monetarni uslovi poboljšani možemo doći samo upoređivanjem industrijske proizvodnje sa $\mathrm{MCl}$ (Grafikon 2). U posmatranom periodu Pearson-ov koeficijent korelacije je 0,55 , a ako isključimo maksimum (eng. outlier) u Q4 2008. godine korelacija u periodu Q1 2009 - Q2 2017. godine iznosi 0,83.

Ovakav odnos je konačan dokaz da su monetarni uslovi poboljšani u odnosu na stopu rasta industrijske proizvodnje, a ne samo u odnosu na $\mathrm{MCl}$ u baznoj godini. 
Grafikon 2: $\mathrm{MCl}$ i industrijska proizvodnja

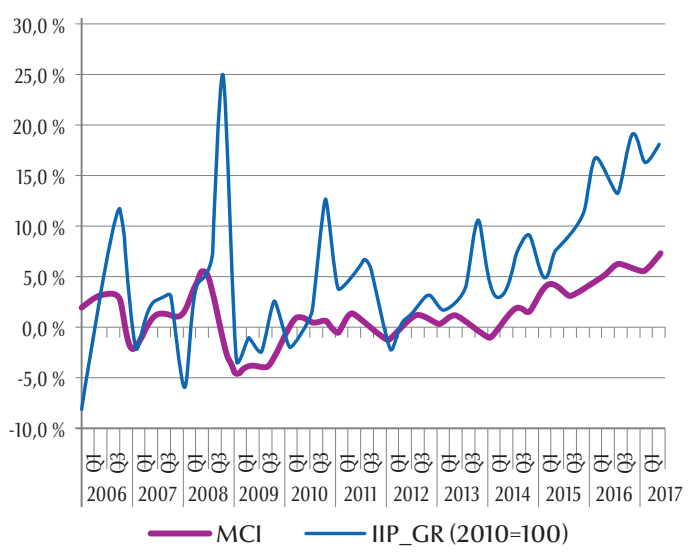

Izvor: Autor.

\section{Negativna naknada na sredstva iznad obavezne rezerve}

Odluka o negativnim naknadama na višak rezervi je stupila na snagu početkom jula 2016. godine. Odluka je donijeta krajem marta 2016. godine i od tada se uočavaju značajane promjene na stopama prinosa do dospijeća na primarnom tržištu javnog duga bh entiteta, tj. na prinos do dospjeća.

Grafikon 3: Prinos do dospjeća, šestomjesečni trezorski zapisi - Republika Srpska (primarno tržište)

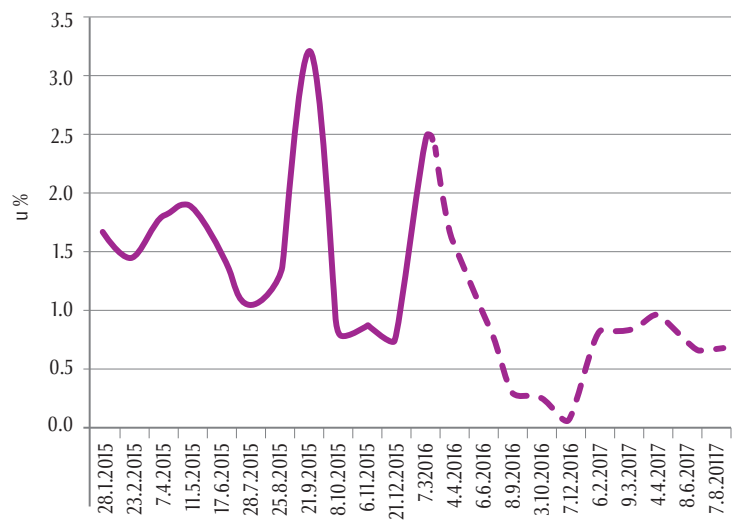

Izvor: BLSE (Obradio autor). Napomena: *Isprekidana linija predstavlja prinose nakon što je donijeta odluka o uvođenju negativne naknade.

$\mathrm{Na}$ oštar pad prinosa na primarnom tržištu utiču negativne naknade na višak rezervi, koja je određena kao polovina kamatne stope na depozitne olakšice ECB $(-0,4 \%$, tj. $-0,2 \%)$. Nakon uvođenja negativne naknade na kratkoročni 
javni dug Republike Srpske najmanji prinos je iznosio 0,1\%, a Federacija BiH imala je negativne prinose na trezorske zapise čak pet puta.

$\mathrm{Na}$ osnovu testa sume rangova (Wilcoxon test) prije i nakon uvođenja negativne naknade (Tabela 4), postoji veoma značajna razlika u prinosima na $6 \mathrm{~m}$ $T Z(R S)$ i $3 \mathrm{~m} \mathrm{TZ}(F B i H)$. Za ove tržišne segmente $\mathrm{p}$ vrijednosti su vrlo niske 0,0037 i 0,016 tako da možemo odbiti nultu hipotezu o jednakosti prinosa prije i nakon uvođenja negativne naknade. Na tržištu šestomjesečnih trezorskih zapisa Federacije BiH, ova razlika u prinosima nije toliko očigledna i tako visoka, ali čak i na ovom tržištu možemo odbiti nultu hipotezu (na nivou od $10 \%$ ) i tvrditi da u $90 \%$ slučajeva postoji razlika u prinosima prije i nakon uvođenja ove jedinstvenog instrumenta bh monetarne politike. Približno isti rezultat dobili smo za devetomjesečne trezorske zapise.

Tabela 4: Kratkoročno primarno tržište javnog duga, test sume rangova

\begin{tabular}{|l|l|l|l|l|}
\hline \multicolumn{1}{|c|}{$\begin{array}{c}\text { Republika } \\
\text { Srpska }\end{array}$} & $\begin{array}{c}\text { Federacija } \\
\text { Bosne i } \\
\text { Hercegovine }\end{array}$ & $\begin{array}{c}\text { Federacija } \\
\text { Bosne i } \\
\text { Hercegovine }\end{array}$ & $\begin{array}{l}\text { Federacija Bosne i } \\
\text { Hercegovine }\end{array}$ \\
\hline & $\begin{array}{l}6 \text { mjesečni } \\
\text { trezorski zapisi }\end{array}$ & $\begin{array}{l}3 \text { mjesečni } \\
\text { trezorski zapisi }\end{array}$ & $\begin{array}{l}6 \text { mjesečni } \\
\text { trezorski zapisi }\end{array}$ & $\begin{array}{l}9 \text { mjesečni } \\
\text { trezorski zapisi }\end{array}$ \\
\hline vremenski period & $01 / 2015-08 / 2017$ & $01 / 2015-08 / 2017$ & $01 / 2015-08 / 2017$ & $01 / 2015-08 / 2017$ \\
\hline Z & 2,9 & 2,42 & 1,63 & 1,549 \\
\hline vjerovatnoća $>$ z & 0,0037 & 0,016 & 0,10 & 0,12 \\
\hline
\end{tabular}

Efekte negativnih naknada na dugoročno primarno tržište veoma je teško procjeniti zbog nerazvijenog tržišta javnog duga. Samo za jedan dio tržišta javnog duga imamo dovoljno podataka za analizu. Od 2014. godine Republika Srpska je izdala osam petogodišnjih obveznica (Grafikon 4). Vizuelnom analizom vremenske serije ne možemo utvrditi da li postoji razlika u prinosima prije i nakon uvođenja negativne naknade.

Grafikon 4: Prinos do dospeća, petogodišnje obveznice - Republika Srpska (primarno tržište)

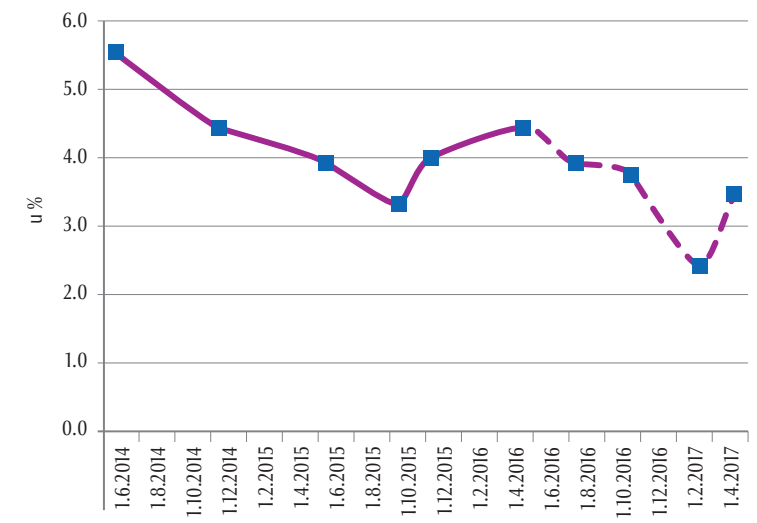


Test sume rangova pokazuje da ovi prinosi nisu u prosjeku drugačiji (Tabela 5). U oba slučaja, u dužem i u kraćem uzorku, ne možemo odbaciti nultu hipotezu, čak ni na nivou od 10\%. P vrijednosti su veoma visoke, pa smo zaključili da negativna naknada nije uticala na prinose na dugoročnom primarnom tržištu javnog duga Republike Srpske.

Tabela 5: Prinos na petogodišnje obveznice primarnog tržišta javnog duga Republike Srpske, test sume rangova

\begin{tabular}{|l|l|l|}
\hline & Republika Srpska & Republika Srpska \\
\hline & Petogodišnje obveznice & Petogodišnje obveznice \\
\hline vremenski period & $01 / 2014-08 / 2017$ & $01 / 2015-08 / 2017$ \\
\hline z & 1,26 & 0,3 \\
\hline vjerovatnoća $>$ z & 0,209 & 0,76 \\
\hline
\end{tabular}

\section{Diferencirana stopa obavezne rezerve (DRRR)}

Model (Tabela 6) objašnjava 86\% varijacija u stopi rasta dugoročnih depozita, a i ukupna dijagnostika modela je dobra; raspodjela reziduala je normalna (statistika Jarque-Berra test), srednja vrjednost reziduala je oko nule, nema heteroskedastičnosti, prema $Q$ statistici autokorelacija je odsutna, uprkos činjenici da $D W$ statistika (autokorelacija u prvoj docnji) pokazuje blagu pozitivnu autokorelaciju. Konstanta u modelu je izostavljena iz ekonomskih, a ne iz statističkih razloga. Model sa konstantom ne bi imao ekonomski logično tumačenje, jer je neprihvatljivo da, ako su sve varijable nula, ipak postoji rast dugoročnih depozita. Možemo reći da su procjene koeficijenata nepristrasne, jer su ispunjeni svi preduslovi za BLUE (najbolja linearna nepristrasna ocjena). Svi koeficijenti, uključujući vještačku varijablu za $D R R R$ (vještačka varijabla za makroprudencionu regulaciju ili $D U M_{-} M P R$ ) su statistički značajni na nivou od 5\% ili čak manje (Tabela 6). Ako je sve ostalo jednako, uvođenje $D R R R$ će povećati stopu rasta dugoročnih depozita za 3,4 procentna poena (p.p.), a među odabranim nezavisno-promenljivim varijablama ova varijabla je najuticajnija. Svi ostali regresori, $E U R I B O R$, stopa rasta $B D P$, stopa rasta kratkoročnih depozita i depozitni multiplikator, podstiču stopu rasta dugoročnih depozita. Logično, znak ispred NPL je negativan, jer neizvjesnost tokom krize i recesije smanjuje tražnju za dugoročnim depozitima i obratno. Zaključujemo da $D R R R$, u okruženju drugih važnih varijabli, značajno utiče na ročnu strukturu obaveza bh banaka tj. u prosjeku doprinosi rastu finansijske stabilnosti. To znači da je ovaj dio makroprudencione regulacije koji je primjenjivala CBBiH djelotvoran. 
Tabela 6: Efekti $D R R R$ na stopu rasta dugoročnih depozita

\begin{tabular}{|c|c|c|c|c|}
\hline & Koeficijenti & S.G. & $\mathrm{t}$ & $p$ \\
\hline DUM_MPR & $3,40^{* *}$ & 1,66 & 2,05 & 0,05 \\
\hline EURIBOR(-2) & $2,65^{* *}$ & 0,99 & 2,67 & 0,01 \\
\hline NPL(-4) & $-0,70 * *$ & 0,26 & $-2,66$ & 0,02 \\
\hline GDP_GR(-7) & $1,05^{* * *}$ & 0,17 & 6,13 & 0,00 \\
\hline STD_GR(-1) & $0,17^{* *}$ & 0,08 & 2,13 & 0,05 \\
\hline $\begin{array}{l}\text { Depozitni multiplikator } \\
\text { multiplikator }\end{array}$ & $0,95^{* *}$ & 0,40 & 2,36 & 0,03 \\
\hline $\mathrm{R}^{2}$ & 0,86 & & & \\
\hline Prilagođeni $\mathrm{R}^{2}$ & 0,83 & & & \\
\hline DW statistika & 1,8 & & & \\
\hline LM test & $0,044(0,84)$ & & & \\
\hline Statistika Jarque-Berra test & $0,63(7.26)$ & & & \\
\hline Srednja vrijednost reziduala & 0,026 & & & \\
\hline Breusch-Pagan-Godfrey test & $7,24(0,337)$ & & & \\
\hline Broj stepeni slobode & 20 & & & \\
\hline Period & 2010Q4-2017Q1 & & & \\
\hline
\end{tabular}

Izvor: BLSE (Obradio autor). Napomena: *** Značajno na nivou od 1\%, ** Značajno na nivou od 5\%, * Značajno na nivou od $10 \%$.

\section{Obavezna rezerva}

U modelima smo koristili varijable u nivou, stope rasta, kao i varijable sa docnjama i pokretne prosjeke. Ove serije nisu kointegrisane. Uslov za kointegraciju je da su sve varijable u modelu I(1) tj. u nivou nestacionarne, a nakon diferenciranja stacionarne I(0). Na osnovu ADF testa (Augmented Dickey-Fuller test) smo utvrdili da ovaj uslov nije ispunjen i zato nije bilo potrebe za prilagođavanjem vremenskih serija. U sva četiri modela (Tabela 7) samo nekoliko regresora su statistički značajni na nivou od 5\% i iznad. Nivo značaja je najčešće ispod 5\%, pa čak i ispod 1\%. Kvalitet modela, mjeren koeficijentom determinacije, je vrlo visok - iznad 0,9. Visok $\mathrm{R}^{2}$ nije posljedica nestacionarnosti vremenskih serija, već dobre specifikacije modela. Lažna regresija (eng. spurious regression) postoji ako je Durbin-Votsonova statistika manja od $\mathrm{R}^{2}$, ako je vrijednost $t$ statistike izuzetno visoka, ako postoji pozitivna autokorelacija i ako je $D W$ izuzetno nizak, što nije slučaj u prezentovanim specifikacijama modela. Osim $R O E$ i $L A(E Q 1, E Q 2)$, svi regresori imaju očekivani znak, u skladu sa ekonomskom teorijom. Kod svih modela znak $R R R$ (zatamnjen red) je negativan, a uzima vrijednost $\mathrm{u}$ intervalu od $-0,63$ do $-0,10$. Promjene u stopi rasta kredita $(L G R)$ i obaveznoj rezervi $(R R R)$ imaju suprotne znakove. Najbolju dijagnostiku ima najmanji model, četvrti (EQ4), koji je ispunio sve uslove za BLUE. Suprotno ostalim modelima, samo četvrti model nema autokorelaciju na višim docnjama. $U$ ovom modelu, osim $R R R$ zavisne varijable su i: stopa rasta kredita, stopa rasta industrijske proizvodnje, stopa rasta depozita, $C P I$ i pokretni prosjek. Sve ove jednačine, posebno četvrta, pokazuju da $R R R$ proizvodi statistički značajan 
efekat, očekivanog smjera, na rast kredita. $R R R$ je kao diskrecioni instrument monetarne politike ispoljio djelotvornost.

Tabela 7: Obavezna rezerva i stopa rasta kredita

\begin{tabular}{|c|c|c|c|c|}
\hline & EQ1 & $\mathrm{EQ} 2$ & EQ3 & EQ4 \\
\hline & $L G R$ & LGR & LGR & LGR \\
\hline LGR(-1) & $\begin{array}{l}0,69 * * * \\
(12,68)\end{array}$ & $\begin{array}{l}0,80^{* * *} \\
(15,97)\end{array}$ & $\begin{array}{l}0,74^{* * * *} \\
(25,31)\end{array}$ & $\begin{array}{l}0,73^{* * * *} \\
(34,22)\end{array}$ \\
\hline ROE & & $\begin{array}{l}-0,15^{* *} \\
(-2,33)\end{array}$ & & \\
\hline ROEA & $\begin{array}{l}-0,30 * * * \\
(-2,77)\end{array}$ & & & \\
\hline IIP_GR & & $\begin{array}{l}0,06^{*} \\
(2,00)\end{array}$ & $\begin{array}{l}0,07^{* *} \\
(2,40)\end{array}$ & $\begin{array}{l}0,08^{* *} \\
(2,64)\end{array}$ \\
\hline GDP_GR & $\begin{array}{l}0,16^{*} \\
(1,84)\end{array}$ & & & \\
\hline DGR & $\begin{array}{l}0,16^{* *} \\
(2,33)\end{array}$ & $\begin{array}{l}0,21^{* * *} \\
(8,04)\end{array}$ & $\begin{array}{l}0,21^{* * *} \\
(8,42)\end{array}$ & $\begin{array}{l}0,25^{* * *} \\
(14,77)\end{array}$ \\
\hline $\mathrm{CPI}$ & $\begin{array}{l}0,29 * * \\
(2,39)\end{array}$ & $\begin{array}{l}0,36^{* * *} \\
(3,306)\end{array}$ & $\begin{array}{l}0,55^{* * *} \\
(5,87)\end{array}$ & $\begin{array}{l}0,60 * * * \\
(8,81)\end{array}$ \\
\hline RRR & $\begin{array}{l}-0,63^{* * *} \\
(-3,13)\end{array}$ & $\begin{array}{l}-0,40^{* *} \\
(-2,71)\end{array}$ & & \\
\hline $\operatorname{RRR}(-2)$ & & & & $\begin{array}{l}-0,12 * * * \\
(-10,30)\end{array}$ \\
\hline RRR(-3) & & & $\begin{array}{l}-0,10 * * * \\
(-3,95)\end{array}$ & \\
\hline LA & $\begin{array}{l}0,11^{* * *} \\
(2,85) \\
\end{array}$ & $\begin{array}{l}0,084^{* *} \\
(2,50)\end{array}$ & & \\
\hline DUM_CRISES & $\begin{array}{l}-2,03^{* *} \\
(-2,03)\end{array}$ & & & \\
\hline $\begin{array}{l}\text { DUM_CRISES } \\
(-2)\end{array}$ & & $\begin{array}{l}-2,5^{* *} \\
(-2,08)\end{array}$ & & \\
\hline $\mathrm{MA}(2)$ & & & & $\begin{array}{l}-0,86^{* *} \\
(3,07)\end{array}$ \\
\hline Vremenski period & 2009Q1 - 2017Q1 & 2007Q3 - 2017Q1 & 2007Q4 -2017Q1 & 2007Q3-2017Q1 \\
\hline
\end{tabular}

Tabela 8: Dijagnostika

\begin{tabular}{|l|l|l|l|l|}
\hline \multicolumn{1}{|c|}{ EQ1 } & \multicolumn{1}{c|}{ EQ2 } & \multicolumn{1}{c|}{ EQ3 } \\
\hline $\mathrm{R}^{2}$ & 0,91 & 0,99 & 0,99 & 0,99 \\
\hline Prilagođeni $\mathrm{R}^{2}$ & 0,89 & 0,98 & 0,98 & 0,98 \\
\hline $\begin{array}{l}D W \\
\text { statistika }\end{array}$ & 1,60 & 1,78 & 1,55 & 1,65 \\
\hline $\begin{array}{l}\text { LM } \\
\text { test-prva docnja }\end{array}$ & $\begin{array}{l}1,40 \\
(0,235)\end{array}$ & $\begin{array}{l}0,07 \\
(0,79)\end{array}$ & $\begin{array}{l}1,62 \\
(0,21)\end{array}$ & - \\
\hline
\end{tabular}




\begin{tabular}{|l|l|l|l|l|}
\hline \multicolumn{1}{|c|}{ EQ1 } & \multicolumn{1}{c|}{ EQ2 } & \multicolumn{1}{c|}{ EQ3 } \\
\hline Q statistika & $\begin{array}{l}\text { AK na višim } \\
\text { docnjama }\end{array}$ & $\begin{array}{l}\text { AK na višim } \\
\text { docnjama }\end{array}$ & $\begin{array}{l}\text { AK na višim } \\
\text { docnjama }\end{array}$ & nema AK \\
\hline $\begin{array}{l}\text { Statistika Jarque- } \\
\text { Berra testa }\end{array}$ & $\begin{array}{l}1,82 \\
(0,4)\end{array}$ & $\begin{array}{l}0,08 \\
(0,96)\end{array}$ & $\begin{array}{l}0,29 \\
(0,86)\end{array}$ & $\begin{array}{l}1,81 \\
(0,407)\end{array}$ \\
\hline $\begin{array}{l}\text { Srednja vrijednost } \\
\text { reziduala }\end{array}$ & 0 & 0 & 0 & 0 \\
\hline $\begin{array}{l}\text { Breusch-Pagan- } \\
\text { Godfrey test }\end{array}$ & $\begin{array}{l}6,75 \\
(0,56)\end{array}$ & $\begin{array}{l}8,68 \\
(0,394)\end{array}$ & $\begin{array}{l}2,70 \\
(0,75)\end{array}$ & $\begin{array}{l}8,12 \\
(0,15)\end{array}$ \\
\hline $\begin{array}{l}\text { Broj stepeni } \\
\text { slobode }\end{array}$ & 25 & 31 & 33 & 33 \\
\hline
\end{tabular}

Izvor:Autor.

\section{Zaključak}

Analizirali smo efekte monetarne politike BiH u periodu Q1 2006 - Q2 2017. primjenom četiri različite metodologije. BH monetarna politika ne može direktno da utiče na bh kamatne stope i na realni efektivni devizni kurs (REER). Uprkos ovoj činjenici, monetarni uslovi su se poboljšali od 2014. godine, sa aspekta industrijske proizvodnje, u poređenju sa periodom nakon izbijanja globalne ekonomske krize. Poboljšanje monetarnih uslova je dokaz da REER, kao automatski instrument monetarne politike, može biti djelotvoran i da kanal kamatne stope djelimično funkcioniše. Negativna naknada na višak rezervi prouzrokovala je negativan prinos do dospjeća na kratkoročni javni dug, po prvi put u istoriji bh monetarne politke. Sa rastom ročnosti javnog duga bh entiteta, efekti negativnih naknada na stopu prinosa na primarnom tržištu se smanjuju. Diferencirana stopa obavezne rezerve (veća na kratkoročne depozite, a niža na dugoročne depozite) je doprinjela ekstenziji ročnosi pasive bh bankarskog sektora. Između stope obavezne rezerve kao instrumenta monetarne politike i kreditnog rasta postoji jaka negativna međuzavisnost.

Glavni naučni doprinos istraživanja je u egzaktnom, empirijskom i ekonometrijskom odbacivanju teze da je bh emisiona banka "obična mjenjačnica“ i da u režimu valutnog odbora BiH nije moguće voditi autonomnu, diskrecionu i efektivnu monetarnu i makroprudencionu politiku i regulaciju. Donosioci ekonomskih odluka u BiH bi trebalo da budu svjesni efekata monetarne politike i njenih instrumenta, te moraju insistirati na njihovom daljem razvoju, kao i na uspostavljanju odgovornosti Centralne banke BiH za stanje u bh ekonomiji. Instrumentima monetarne politike $\mathrm{CBBiH}$ može uticati i na realne i na finansijske varijable $u$ bh ekonomiji.

Izgradnja modela (VAR, VECM, SVAR), kako bi se pratili efekti bh monetarne politike na realne i finansijske varijable su neki od pravaca za buduća istraživanja ove vrste. Zanimljivo bi bilo i izolovati efekte bh monetarne politike na krivu prinosa u Republici Srpskoj i objasniti razlike u odnosu na krivu prinosa u Federaciji Bosne i Hercegovine. Naučni iskorak bi bio i objašnjenje kreditne i depozitne multiplikacije u monetarnom režimu sa negativnom naknadom na sredstva iznad obavezne rezerve. 


\section{Reference}

1. Žižić, Mileva, Lovrić, Miodrag i Pavličić, Dubravka. (1992). Metodi statističke analize. Beograd: Savremena administracija.

2. Benazić, Manuel. (2012). Monetary Policy Index for Croatia. Economic Research. Vol. 25, SE 1: 47-64.

3. Calvo, Guillermo.(1999). Fixed versus Flexible Exchange Rates. University of Maryland. https://drum.lib.umd.edu/bitstream/handle/1903/4295/ciecrp10.pdf?sequence=1 (accessed 20.9.2017).

4. Fleming, John. (1963). Domestic financial policies under fixed and floating exchange rates. IMF Staff Papers, 9,369-379.

5. Helmi, Mohamad. (2011).Modeling Monetary Policy Rules in the MENA Countries: Issues and Evidence. International Journal of Social Sciences and Humanity Studies, Vol 3, No.2. http://www.sobiad.org/eJOURNALS/journal_IJSS/arhieves/2011_2/ mohamad_husam_helmi.pdf (accessed 20.9.2017).

6. Jović, Dragan. (2017). Ekspanzivna monetarna politika Centralne banke Bosne i Hercegovine i stopa prinosa do dospjeća na primarnom tržištu kratkoročnog javnog duga bosanskohercegovačkih entiteta. Računovodstvo i poslovne finansije, br. 09/2017: 47-50.

7. Kodra, Oriela. (2010). Estimation of Weights for the Monetary Conditions Index in Albania. Tirana: $4^{\text {th }}$ Annual SEE Economic Research Workshop.

8. Neil, R.Ericsson, Eilev, S. Jansen, Kerbeshian, A. Neva, and Ragnar, Nymoen. (2012). Interpreting a Monetary Conditions Index in Economic Policy. http://www.bis.org/ publ/confp06i.pdf (accessed 16.08.2017).

9. Obstfeld, Maurice i Rogoff, Kenneth. (1995). "The Mirage of Fixed Exchange Rates", Journal of Economic Perspectives 9 (4), 73-96.

10. Osborne, Jenny-Kinch i Holton, Sarah. (2010). A Discussion of Monetary Condition Index". ESCB, Bilten 01/2010. p.p. 68-80.

11. Rey, Helene. (2015). Dilemma not Trilemma: The Global Financial Cycle and Monetary Policy Independence. NBER, Working Paper No. 21162.

12. Shambaugh, Jay. (2004). "The Effect of Fixed Exchange Rates on Monetary Policy", Quarterly Journal of Economics 119 (1), 301-352.

13. Svensson, Lars.(1994). "Fixed exchange rates as a means to price stability: What have we learned?", European Economic Review 38 (3-4), 447-468.

14. Taylor, John.(2000). Using Monetary Policy Rules in Emerging Market Economies. Stanford University. https://pdfs.semanticscholar.org/ a729/6bfda8c15865d52955eb37196c5543ea2a18.pdf (accessed 20.9.2017).

15. Vandenbussche, Jérôme, Vogel, Ursula and Detragiache, Enrica. (2012). Macroprudential Policies and Housing Prices-A New Database and Empirical Evidence for Central, Eastern, and Southeastern Europe. WP 12/303. http://dx.doi. org/10.5089/9781475550139.001.

16. Agencija za statistiku Bosne i Hercegovine, www.bhas.ba.

17. Centralna banka Bosne i Hercegovine, www.cbbh.ba.

18. Agencija za bankarstvo Federacije BiH, www.fba.ba.

19. Bank for International Settlements, http://www.bis.org/publ/confp06i.pdf (accessed 16.08.2017).

20. European Central Bank.(2002). Issues related to Monetary Conditions Indices. Monthly Bulletin June. https://ec.europa.eu/info/business-economy-euro/indicators-statistics/ economic-databases/monetary-conditions-index_en (accessed on 15.09.2017.).

21. Hong Kong Monetary Authority. (2010).A Monetary Conditions Index for Hong Kong. Quarterly Bulletin 11. http://www.hkma.gov.hk/media/eng/publication-and-research/ quarterly-bulletin/qb200011/fa02.pdf (accessed 20.09.2017). 
original

scientific paper

\title{
Currency Board,
} Monetary Regulation, and Macroprudential Regulation in Bosnia and Herzegovina

\author{
Dragan Jović, Central Bank of Bosnia and Herzegovina \\ Main Bank of Republika Srpska \\ email: draganjovic@blic.net
}

Translation provided by the author
Summary: This research presents the effects of discretionary and automatic instruments' application in four cases of monetary and macroprudential regulation in Bosnia and Herzegovina. The effectiveness of currency board policy is increasing if its orthodoxy is decreasing. We have measured monetary conditions before and after the global crisis. Monetary conditions had been improving since Q2 2014. The effects of negative remuneration on excess reserves on $\mathrm{BH}$ public debt's primary market are isolated. We have also estimated the effects of the differentiated reserve requirement rate on the maturity structure of $B H$ banking sector's liability. Finally, we tested the relationship between the reserve requirement as a monetary regulation instrument and loan growth. The research showed that the Central Bank of Bosnia and Herzegovina can influence some operative variables/indicators of monetary policy. All findings show that the Central Bank of Bosnia and Herzegovina is not an "ordinary exchange office", and that it can, indeed, conduct autonomous and discretionary monetary policy.

Keywords: monetary policy, currency board, reserve requirement, monetary conditions index, negative remuneration.

JEL: E42, E52, E58, G28 


\section{Introduction}

A widespread way of reasoning about the domestic currency board is that the Central Bank of Bosnia and Herzegovina $(C B B H)$ is an "ordinary exchange office" i.e. it does not conduct autonomous and discretionary monetary policy. This kind of so-called "monetary main stream of thinking" about the $B H$ currency board is the main motivation for the research we want to present. Our main hypothesis is that the $C B B H$ conducts, and is indeed able to conduct monetary policy, even though exchange rate is pegged, even though the domestic key interest rate and the lender of last resort do not exist, and even though there is automatic conversion between the domestic (BAM) and reserve currency (EUR). In order to prove this hypothesis we will exam the behavior of a few instruments of monetary and macroprudential policy. Through the analysis of monetary conditions, reserve requirement, differentiated reserve requirement rate and remuneration on excess reserves, we want to prove the existence of effects of domestic monetary and macroprudential policy, and that they can be conducted by using discretionary and even automatic instruments of monetary and macroprudential policy. In research, monetary policy autonomy is defined as the capability to influence short-term yields and credit growth.

In the first part of this research, we give a review of literature used, followed by the data and methodology. The central part of this research has four sections: a) monetary conditions index, b) negative remuneration on excess reserves, c) differentiated reserve requirement rate, and d) reserve requirement rate. The conclusion and references are at the end of the paper.

\section{Literature Review}

There is no unique view on the degree of monetary policy autonomy in the case of fixed exchange rates, and therefore not in the case of the currency board. Some authors consider a fixed exchange rate to be a good option even in the case of high levels of currency substitution and endogenous shocks (Calvo, 1999). On the other hand, the authors (Obstfeld and Rogoff, 1995) who, analyzing the crisis of the European Exchange Rate Mechanism in 1992, as well as the Mexican crisis (1994-1995), conclude that the fixed exchange rate leads to a loss of control over money supply. The 'impossible trinity' principle states that monetary policy autonomy is impossible in a fixed exchange rate regime and in the absence of capital control (Fleming, 1963), and even in a flexible exchange rate regime, autonomous monetary policy is challenged in conditions of high capital mobility (Rey, 2015). There are also views that a sound monetary policy is based on a trinity of a variable exchange rate, inflation targeting, and a monetary rule (Taylor, 2000), which absolutely rejects the fixed exchange rate regime and even the currency board. In some studies, econometric verification of the hypothesis that the degree of monetary policy autonomy (measured by the ability to influence short-term interest rates) is higher in the flexible exchange rate regime than in the fixed exchange rate regime (Shaumbaugh, 2002). 
The $\mathrm{MCl}$, as a measurement of monetary conditions, has been in use since the end of the last century i.e. since the beginning of the '90s. The interpretation of the $\mathrm{MCl}$ was discussed in Ericsson et al. (2006) and also in Osborne and Holton (2010). The MCI was developed for Hong Kong (HKMA, Quarterly Bulletin 11/2010) and issues related to the $\mathrm{MCl}$ were discussed in the euro zone (ECB, Monthly Bulletin, 2002). Some of the neighboring countries like Croatia, (Benazić, 2012), and Albania, (Kodra, 2010), have developed their MCl. The main conclusion about the $\mathrm{MCl}$ is that there are different methodologies for its calculation, and its value varies a lot depending on used the methodology. In domestic literature, there is only one reference on the negative remuneration on excess reserves (Jović, 2017), which points to its influence on the public debt yields in Bosnia and Herzegovina. We did not find a single research paper on the differentiated reserve requirement rate or on the reserve requirement rate in Bosnia and Herzegovina. On the other hand, a reserve requirement rate has been intensively analyzed in foreign literature, which is not the case with the impact of a differentiated reserve requirement rate (DRRR) on the maturity structure and on the banking sector's liabilities. The main research in this area (IMF, 2011 and IMF 2013) showed that a reserve requirement rate $(R R R)$ reduces the procyclicality of banking loans and that the RRR can reduce portfolio investments in countries with flexible foreign exchange. Marginal reserve requirement on banks' foreign liabilities with the use of capital requirement decelerates real estate price growth in emerging Europe, (Vandenbussche et al 2012), while the RRR on short-term liabilities reduces credit growth.

\section{Data and Methodology}

We have estimated the effects of the $B H$ monetary and macroprudential regulation in four ways. The first way is the measurement of monetary conditions i.e. the construction of the monetary condition index $(\mathrm{MCl})$. If monetary conditions in $\mathrm{BH}$ are better after the global crisis broke out, then the monetary policy was effective. The second way of measuring the $\mathrm{BH}$ monetary and macroprudential regulation effects is the estimation of the negative remuneration effects. The third and the fourth one are the measurement of differentiated reserve requirement effects and reserve requirement effects on long-term deposits and loan growth rate, respectively.

The Monetary Condition Index $(M C l)$ was invented in Canada at the very end of the twentieth century (during the nineties). In its original form, it was presented as:

$$
M C I=-\left(\alpha\left(i r-i r_{b}\right)+\beta\left(R E E R-R E E R_{b}\right) 100\right)
$$

where are: ir and $i r_{b}$ are the interest rate and interest rate in the base year, and REER and REER the log of real effective exchange rate and log of real effective exchange rate in the base year. We have applied the same form of the $\mathrm{MCl}$ formula in the research. For the base year, we have used 2010, i.e. average for interest rate and REER for this year, because the domestic index of industrial production has the same base year. Some characteristics of 
the $\mathrm{MCl}$ have to be explained. The minus sign in front of the equation is set due to the impact of the interest rate and the real effective exchange rate on monetary conditions and due to ease of interpretation. If interest rates and REER go up, that kind of change is negative and vice versa. Increase in the $\mathrm{MCl}$ represents monetary conditions improving, while a decrease in the $\mathrm{MCl}$ represents monetary conditions worsening. The second part of the equation (i.e. difference in REER) is multiplied with 100 in order to get the change in percentages. There are many ways of $\mathrm{MCl}$ estimation, and we have chosen the original and the simplest one. The coefficients $\alpha$ and $\beta$ are derived from the regression model represented as;

$$
I I P_{g r}=c(1)+c(2) * I I P_{g r}(-1)+c(3) * I R(-1)+c(4) * \text { REER }_{g r}(-1)
$$

where IIP_gr is the industrial production growth rate, and $\mathrm{C}(3)$ is $\alpha$ and $\mathrm{C}(4)$ is $\beta, I R_{-} R$ is the domestic lending rate (banking lending rate), and $R E E R$ is the real effective exchange rate.

In March 2016, for the first time in $\mathrm{BH}$ monetary history, negative remuneration on excess reserves was introduced. The decision entered into force three months later. The $C B B H$ linked its remuneration on excess reserves to the $E C B^{\prime}$ s deposit facility interest rate. In the time when the decision was made this rate was negative, $-0.4 \%$. We have captured the effects of this change with the Wilcoxon - Mann - Whitney test, i.e. the rank-sum test. This test tries to figure out if there is a difference between observations exposed to different treatments. In our case, the treatment is negative remuneration on excess reserves i.e. the absence of negative remuneration on excess reserves. We have observed the effects of the remuneration on $B H$ entities' (Republic of Srpska/RS and Federation of Bosnia and Herzegovina/FBH) treasury market or precisely on primary market's yields and on bond yields (also on the primary market). Our assumption is that there must be a difference in yields before and after the introduction of negative remuneration. With a rank-sum test, a sort of nonparametric test (Žižić et al., 1992. p. 351), we have checked this thesis. The null hypothesis in this test is that the value of the observation is equal before and after the introduction of negative remuneration.

Since 1 January 2009 and until 1 July 2016, the BH monetary regime had operated with $D R R R$. There were lower reserve requirements on long-term deposits and higher reserve requirements on short-term deposits (Table 1). At the beginning of this kind of reserve requirement regime, as a sort of macroprudential regulation, the $R R R$ was $14 \%$ for short-term deposits and $10 \%$ for long-term deposits.

Table 1: $D R R R$ in Bosnia and Herzegovina

\begin{tabular}{|l|l|l|l|l|}
\hline & \multicolumn{1}{|c|}{$\begin{array}{c}1 \text { January } \\
2009\end{array}$} & $\begin{array}{c}1 \text { May } \\
2009\end{array}$ & $\begin{array}{c}1 \text { February } \\
2011\end{array}$ & \multicolumn{1}{l|}{$\begin{array}{l}\text { 1 July } \\
2016\end{array}$} \\
\hline $\begin{array}{l}\text { RRR on liabilities } \\
\text { with maturity below 1 year }\end{array}$ & $14 \%$ & $14 \%$ & $10 \%$ & $10 \%$ \\
\hline $\begin{array}{l}\text { RRR on liabilities } \\
\text { with maturity above 1 year }\end{array}$ & $10 \%$ & $7 \%$ & $7 \%$ & $10 \%$ \\
\hline
\end{tabular}

Source: $\mathrm{CBBH}$. 
We have used multiple regression models (the parameters in models were estimated by the ordinary least square method/OLS) to find a connection between the $D R R R$ and long-term deposits' growth rate. For that purpose we have introduced the model dummy for $D R R R$ with a value of 1 in the period 01/2009-06/2016. The other regressors were EURIBOR, and domestic variables: nonperforming loans, GDP growth rate, short-term deposits' growth rate and deposit multiplier (inverse value of the reserve requirement rate).

In order to test the effects of the $R R R$ on the credit growth, the multiple linear regression model was also used. Besides the $R R R$, we have introduced into the model a lot of regressors and controlled variables: credit growth lags, return on equity, industrial production growth rate, GDP growth rate, deposit growth rate, $\mathrm{CPI}$, loan to asset ratio (LA), dummy (for the withdrawal of foreign liabilities from BH banking sector, 03/2009 - 06/2016 =1) and moving average. The diagnostics for all models include checking for autocorrelation (Durbin-Watson test, $L M$ test, $Q$ statistics), normality (Jarque-Berra test), and homoscedasticity (Breusch-Pagan-Godfrey test). In order to facilitate the presentation, a lot of abbreviations were used. The number of degrees of freedom is defined as $n-k$, where $n$ is number of observations, and $k$ is number of parameters (including a constant, if it exists) to be estimated.

In order to facilitate the presentation of results we used many abbreviations (acronyms are derived from the names in English, and not in Serbian).

Table 2: List of Abbreviations and Sources of Time Series

\begin{tabular}{|l|l|l|l|}
\hline No. & Abbreviation & & \multicolumn{1}{|c|}{$\begin{array}{l}\text { Tources of } \\
\text { time series }\end{array}$} \\
\hline 1 & BSBH & Banking Sector of Bosnia and Herzegovina & - \\
\hline 2 & BSFBH & $\begin{array}{l}\text { Banking Sector of the Federation of Bosnia and } \\
\text { Herzegovina }\end{array}$ & - \\
\hline 3 & CBBH & Central Bank of Bosnia and Herzegovina & - \\
\hline 4 & CPI & Consumer Price Index & BHAS \\
\hline 5 & DGR & Deposit Growth Rate & CBBH \\
\hline 6 & DUM_CRISIS & $\begin{array}{l}\text { Dummy for Crisis i.e. } \\
\text { for the withdraw of foreign liabilities from BSBH }\end{array}$ & - \\
\hline 7 & DUM_MPR & Dummy for Macroprudential Regulation & - \\
\hline 8 & DRRR & Differentiated Reserve Requirement Rate & CBBH \\
\hline 9 & DW & Durbin-Watson Statistics & - \\
\hline 10 & EURIBOR & 12 month & ECB \\
\hline 11 & GDP & Gross Domestic Product & BHAS \\
\hline 12 & GDP_GR & Gross Domestic Growth Rate & BHAS \\
\hline 13 & IIP & Index of Industrial Production & BHAS \\
\hline 14 & IP_GR & Industrial Production Growth Rate & BHAS \\
\hline 15 & IMF & International Monetary Fund & - \\
\hline 16. & LA & Loan to Asset Ratio & CBBH \\
\hline 17. & LGR & Loan Growth Rate & CBBH \\
\hline 18. & LR & Domestic Lending Rate & ABRS and FBA \\
\hline 19. & MCI & Monetary Conditions Index & CBBH \\
\hline 20. & NPL & Nonperforming Loans & \\
\hline & & & \\
\hline
\end{tabular}




\begin{tabular}{|l|l|l|l|}
\hline No. & Abbreviation & \multicolumn{1}{|c|}{ Term } & \multicolumn{1}{c|}{$\begin{array}{c}\text { Sources of } \\
\text { time series }\end{array}$} \\
\hline 21. & REER & Real Effective Exchange Rate & CBBH \\
\hline 22. & REER_GR & Real Effective Exchange Rate Growth Rate & CBBH \\
\hline 23. & ROAE & Return on Average Equity & CBBH \\
\hline 24. & ROE & Return on Equity & CBBH \\
\hline 25. & RRR & Reserve Requirement Rate & CBBH \\
\hline 26. & STD_GR & Short-Term Deposits Growth Rate & CBBH \\
\hline 27. & TB & Treasury Bills & - \\
\hline
\end{tabular}

\section{Results and Discussion}

\section{Monetary Conditions Index (MCI)}

The regression model we created is a very good representation of the relation between industrial production and interest rates/real effective exchange rate (Table 3). Almost all coefficients are significant at $1 \%$ level and below. The values of coefficients with the regressors lending rate $(L R)$ and real effective exchange rate growth rate (REER_GR) are -1.66 and -2.12 , respectively. These coefficients, as expected, have a negative sign i.e. growth in $L R$ and REER_GR decreases the value of industrial production growth. According to the model's diagnostic, coefficients are unbiased estimates of parameter values. Neither autocorrelation nor heteroscedasticity exist in this model. The distribution of residuals is normal, and the residual's mean is zero.

Table 3: Regression model, dependent variable - industrial production growth rate

\begin{tabular}{|l|l|l|l|l|}
\hline & \multicolumn{1}{|c|}{ Coefficient } & \multicolumn{1}{c|}{ S.E. } & \multicolumn{1}{c|}{ T } & \multicolumn{1}{c|}{ Prob. } \\
\hline C & 8.16 & 2.18 & 3.75 & 0.0006 \\
\hline IIP_GR-(-1) & 0.33 & 0.13 & 2.59 & 0.0141 \\
\hline LR & -1.66 & 0.43 & -3.90 & 0.0004 \\
\hline REER_GR & -2.12 & 0.68 & -313 & 0,0035 \\
\hline & & & & \\
\hline R $^{2}$ & 0.45 & & & \\
\hline Adjusted R & 0.38 & & & \\
\hline DW statistics & 1.99 & & & \\
\hline $\begin{array}{l}\text { Q-statistics } \\
\text { (first or second lag) }\end{array}$ & $0.0131(0.909)$ & & & \\
\hline JB statistics & $2.71(0.26)$ & & & \\
\hline Mean value of residuals & 0 & & & \\
\hline $\begin{array}{l}\text { Breusch-Pagan-Godfrey } \\
\text { test }\end{array}$ & $6.07(0.108)$ & & & \\
\hline $\begin{array}{l}\text { The number of degrees of } \\
\text { freedom }\end{array}$ & 37 & & & \\
\hline Period & $2007 Q 2-2017 Q 2$ & & & \\
\hline
\end{tabular}

Source: Author 
The model is the base for $\mathrm{MCl}$ construction. Applying it, we got following formula for Bosnia's $\mathrm{MCl}$ index,

$$
\begin{aligned}
& M C I=-\left(-1.66\left(i r-i r_{b}\right)-2.12\left(R E E R-R E E R_{b}\right) 100\right) \text { or } \\
& M C I=-\left(\frac{1.66}{2.12}\left(i r-i r_{b}\right)+\left(R E E R-R E E R_{b}\right) 100\right)
\end{aligned}
$$

The Bosnian $\mathrm{MCl}$ shows that monetary conditions have been improving since Q2 2014 (Graph 1), compared to the chosen base period ( $\varnothing$ Q32007 - Q42008). There is a high correlation in the movements of the REER and the $M C l$, because the REER is a main contributor to the $M C I$ (Graph 1). The calculated $\mathrm{MCl}$ ratio of $0.78(1.66 / 2.12)$ is very low compared to the usual one and the contribution to the $\mathrm{MCl}$ is higher in the case of REER. The reasonable explanation for this fact could be the absence of the domestic central bank reference rate. The contribution of the REER to the $\mathrm{MCl}$ is higher than in the case of interest rates, due to the higher decrease (depreciation) in the REER than in interest rates comparing to the base period. Hence, the foreign exchange channel in $\mathrm{BH}$ is more important and more intensive then the interest rate channel. Movements in the REER are totally out of control of domestic monetary policy, and it means that monetary conditions in Bosnia are mainly influenced by automatic factors, and not by discretionary monetary policy instruments.

Graph 1: Monetary Policy Index in Bosnia and Herzegovina

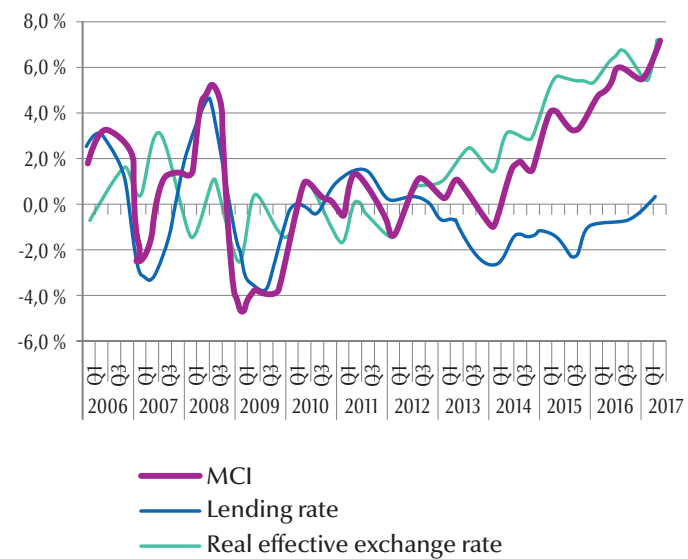

Source: Author

In 2016 and in the first two quarters of 2017, the $\mathrm{MCl}$ is much higher than the base $\mathrm{MCl}$ (it is around 6\% higher), but we can reach a final conclusion about improving monetary conditions only by comparing the industrial production growth rate and the $\mathrm{MCl}$ (Graph 2). During the entire observed period, the correlation coefficient (Pearson's correlation coefficient) was 0.55 , and if we exclude the peak in Q4 2008, the correlation in the period Q1 2009 - Q2 2017 was 0.83 . This kind of relation is the final proof that monetary conditions are improved in relation to the industrial production growth rate and not only in relation to the $\mathrm{MCl}$ in the base year. 
Graph 2: $\mathrm{MCl}$ and Industrial Production

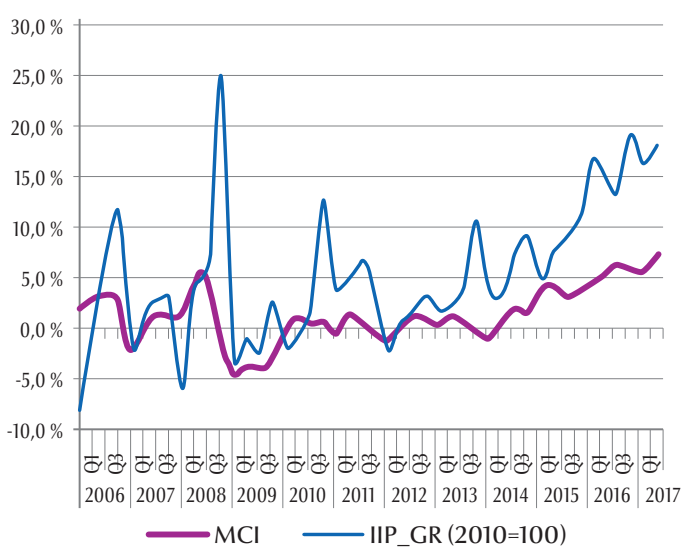

Source: Author.

\section{Negative Remuneration on Excess Reserves}

The decision on the negative remuneration on excess reserves entered into force at the beginning of July 2016. The decision was made at the end of March 2016 and since then we have been able to see a significant effect on the primary market i.e. on the yield to maturity.

Graph 3: Yield to Maturity, 6 Months Treasury Bill - Republic of Srpska (primary market)

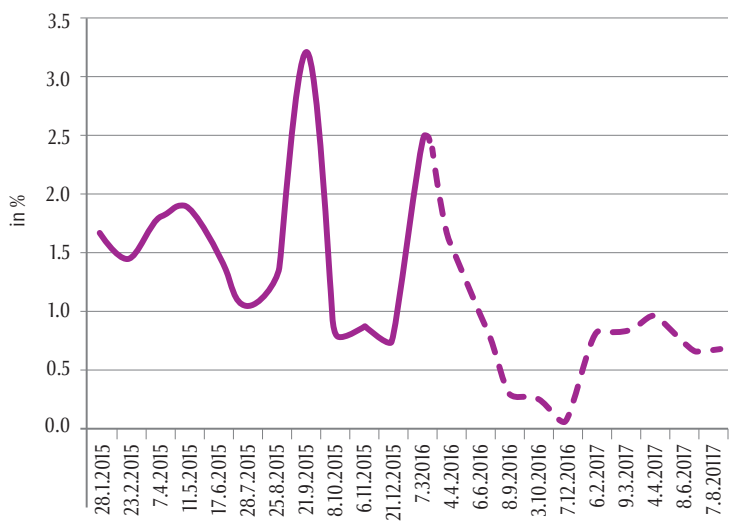

Source: BLSE (Author). Note: * Dashed line represents yields after negative remuneration entered into force.

The sharp decline in yields on the primary market is influenced by negative remuneration set at a half of the interest rate on $E C B$ deposit facility rate $(-0.4$, i.e. $-0.2 \%)$. After introducing negative remuneration on the short-term debt of 
the Republic of Srpska, the lowest yield was $0.1 \%$, and Federation of $B H(F B H)$ had negative yields on short-term debt instruments as many as five times.

According to the Wilcoxon test, there is a very significant difference in yields on $6 \mathrm{~m} \mathrm{~TB}(R S)$ and $3 \mathrm{~m} \mathrm{~TB}(F B H)$ before and after introducing negative remuneration (Table 4). For these markets $P$ values are very low 0.0037 and 0.016 so we can reject the null hypothesis on the equality of yields before and after negative remuneration. On $6 \mathrm{~m} \mathrm{~TB}$ market in Federation $B H$ this difference in yields is not so obvious and so high, but even in this market we can reject the null hypothesis at $10 \%$ level, and claim that in $90 \%$ of cases there is a difference in yields before and after this extraordinary measure of domestic monetary policy. Approximately the same result was reached for 9 month treasury bills.

Table 4: Short-Term Primary Market of Public Debt, Wilcoxon Rank-Sum Test

\begin{tabular}{|l|l|l|l|l|}
\hline & \multicolumn{1}{|c|}{$\begin{array}{c}\text { Republic of } \\
\text { Srpska }\end{array}$} & $\begin{array}{c}\text { Federation of } \\
\text { Bosnia and } \\
\text { Herzegovina }\end{array}$ & $\begin{array}{c}\text { Federation of } \\
\text { Bosnia and } \\
\text { Herzegovina }\end{array}$ & $\begin{array}{c}\text { Federation of } \\
\text { Bosnia and } \\
\text { Herzegovina }\end{array}$ \\
\hline & $\begin{array}{l}6 \text { months } \\
\text { Treasury Bills }\end{array}$ & $\begin{array}{l}3 \text { months } \\
\text { Treasury Bills }\end{array}$ & $\begin{array}{l}6 \text { months } \\
\text { Treasury bills }\end{array}$ & $\begin{array}{l}\text { 9 months } \\
\text { Treasury bills }\end{array}$ \\
\hline time period & $01 / 2015-08 / 2017$ & $01 / 2015-08 / 2017$ & $01 / 2015-08 / 2017$ & $01 / 2015-08 / 2017$ \\
\hline Z & 2.9 & 2.42 & 1.63 & 1.549 \\
\hline probability $>z$ & 0.0037 & 0.016 & 0.10 & 0.12 \\
\hline
\end{tabular}

Source: Author

The effects of negative remuneration on the long-term primary market are very hard to precisely determine, due to the underdeveloped debt market. We have sufficient data for analysis only for a single part of debt market. Since 2014, the Republic of Srpska has issued eight 5-year bonds in total (Graph 4). By visual inspection alone, we cannot determine without a doubt whether there is a difference in the average yields before and after the negative remuneration entered into force.

Graph 4: Yield to Maturity, 5-Year Bond - Republic of Srpska (primary market)

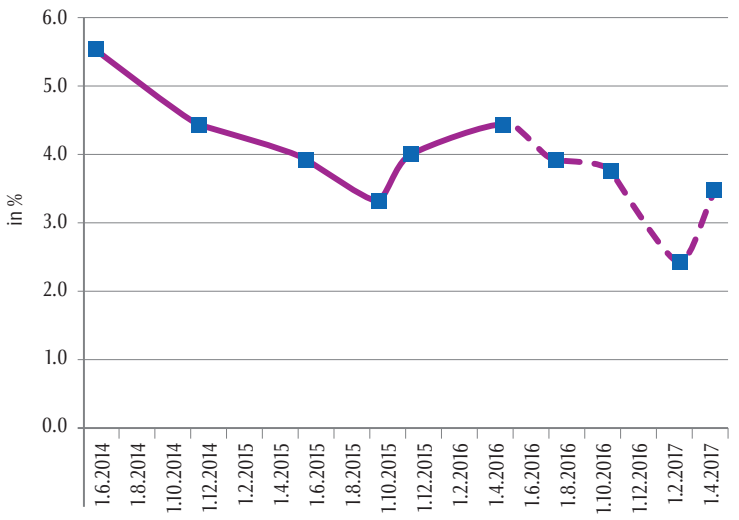


But, the Wilcoxon rank-sum test shows for certain that these yields are not on average different (Table 5). In both cases, in the long and short sample, we cannot reject the null hypothesis, not even at the level of 10 percent. $P$ values are very high, so we have concluded that negative remuneration did not influence yields on the long-term primary market of the Republic of Srpska.

Table 5: Yields on Five-Year Bond Primary Market of Public Debt of the Republic of Srpska, Wilcoxon Rank-Sum Test

\begin{tabular}{|l|l|l|}
\hline & \multicolumn{1}{|c|}{ Republic of Srpska } & \multicolumn{1}{c|}{ Republic of Srpska } \\
\hline time period & 5-Year Bond & 5-Year Bond \\
\hline$z$ & $01 / 2014-08 / 2017$ & $01 / 2015-08 / 2017$ \\
\hline probability $>$ Z & 1.26 & 0.3 \\
\hline & 0.209 & 0.76 \\
\hline
\end{tabular}

\section{Differentiated Reserve Requirement Rate (DRRR)}

The model (Table 6) itself explains $86 \%$ of variations in long-term deposits' growth rate, and the overall diagnostic is good; the distribution of residual is normal ( $J B$ statistics), the mean value of residual is around zero, there is no heteroscedasticity, according to the $Q$-statistics, autocorrelation is absent, despite the fact that $D W$ statistics (autocorrelation at first lag) show small positive autocorrelation. The constant in the model is omitted for economic rather than for statistical reasons. A model with a constant would not have an economically logical interpretation, because it is unacceptable that, if all the variables are zero, there is still an increase in long-term deposits. So, we can say that estimates of coefficients are unbiased, because all preconditions for BLUE (best linear unbiased estimator) are satisfied. All coefficients, including the dummy variable for the $D R R R$ (dummy for macroprudential or $D U M_{-} M P R$ ), are significant at $5 \%$, or even less (Table 6). If all others are equal, introducing the $D R R R$ will increase the long-term deposits' growth rate by 3.4 percentage points (p.p.), which means that, among all chosen independent variables, this one is the most influential. All other regressors, EURIBOR, growth rate, shortterm deposits and the deposit multiplier, push long-term deposits' growth rate up. Logically, the sign in front of $N P L$ is negative, because uncertainty during downturn decreases demand for long-term deposits and vice versa. We can conclude that the $D R R R$, in an environment of other important variables, significantly influences the maturity structure of liabilities i.e. on average it extends the maturity of the banking sector and yields to financial stability. It means that this part of macroprudential regulation enforced by the $\mathrm{CBBH}$ was effective. 
Table 6: Effects of the DRRR on Long-Term Deposits' Growth Rate

\begin{tabular}{|c|c|c|c|c|}
\hline & Coefficient & S.E. & $\mathrm{T}$ & Prob. \\
\hline DUM_MPR & $3.40^{* *}$ & 1.66 & 2.05 & 0.05 \\
\hline EURIBOR(-2) & $2.65^{* *}$ & 0.99 & 2.67 & 0.01 \\
\hline $\mathrm{NPL}(-4)$ & $-0.70 * *$ & 0.26 & -2.66 & 0.02 \\
\hline GDP_GR(-7) & $1.05^{* * *}$ & 0.17 & 6.13 & 0.00 \\
\hline STD_GR(-1) & $0.17^{* *}$ & 0.08 & 2.13 & 0.05 \\
\hline $\begin{array}{l}\text { Deposit multiplier } \\
\text { multiplier }\end{array}$ & $0.95^{* *}$ & 0.40 & 2.36 & 0.03 \\
\hline $\mathrm{R}^{2}$ & 0.86 & & & \\
\hline Adjusted R ${ }^{2}$ & 0.83 & & & \\
\hline DW statistics & 1.8 & & & \\
\hline LM test & $0.044(0.84)$ & & & \\
\hline JB statistics & $0.63(7.26)$ & & & \\
\hline Mean value of residuals & 0.026 & & & \\
\hline Breusch-Pagan-Godfrey test & 7.24(0.337) & & & \\
\hline $\begin{array}{l}\text { The number of degrees of } \\
\text { freedom }\end{array}$ & 20 & & & \\
\hline Period & $\begin{array}{l}\text { 2010Q4- } \\
2017 Q 1\end{array}$ & & & \\
\hline
\end{tabular}

Source: BLSE (Author).

\section{Reserve Requirement}

In the models, we used variables in levels, growth rates, as well as lags and moving averages. These series are not cointegrated. The condition for cointegration is that all the variables in the model are I(1), i.e. non-stationary in the level, and, after differentiation, are stationary I (0). Based on the ADF (Augmented Dickey - Fuller test), we determined that this condition was not met and, therefore, no time series adjustment was necessary. In all four models (Table 7 and Table 8) only a few regressors are significant at a 5\% level and above. Mostly, the level of significance is below $5 \%$, and even below $1 \%$. The overall goodness of fit, measured by coefficient of determination, is on a high level, above 0.9 . The high $\mathrm{R}^{2}$ is not due to the non-stationarity of the time series, but due to the good specifications of the models. Spurious regression exists if the Durbin-Watson statistics is less than the $\mathrm{R}^{2}$, if the value of the $t$ statistics is extremely high, if there is positive autocorrelation, and if the $D W$ is extremely low, which is not the case in the presented specifications. Except for the $R O E$ and $L A$ (EQ1, EQ2), all regressors have the expected sign, in accordance with economic theory. In all models, the sign of the $R R R$ (darkened row) is negative and it takes value in the interval between -0.63 and -0.10 . The movements in the loan growth rate and the $R R R$ have opposite signs. The smallest model, the fourth one (EQ4), has the best diagnostics, which have passed all expected conditions. Contrary to other models, only the fourth one has not autocorre- 
lated at higher lags. In this model, dependent variables besides the $R R R$ are: loan growth rate, industrial production growth rate, deposit growth rate, $C P I$, and moving average. All these equations, especially the fourth one, show that the $R R R$ produces statistically significant effect (with the expected sign) on loan growth. It means that, as a discretionary monetary policy instrument, the $R R R$ has showed efficacy.

Table 7: Reserve Requirement and Loan Growth Rate

\begin{tabular}{|c|c|c|c|c|}
\hline & EQ1 & EQ2 & EQ3 & EQ4 \\
\hline & LGR & LGR & LGR & LGR \\
\hline LGR(-1) & $\begin{array}{l}0.69 * * * \\
(12.68)\end{array}$ & $\begin{array}{l}0.80^{* * *} \\
(15.97)\end{array}$ & $\begin{array}{l}0.74^{* * *} \\
(25.31)\end{array}$ & $\begin{array}{l}0.73 * * * \\
(34.22)\end{array}$ \\
\hline ROE & & $\begin{array}{l}-0.15^{* *} \\
(-2.33) \\
\end{array}$ & & \\
\hline ROEA & $\begin{array}{l}-0.30 * * * \\
(-2.77)\end{array}$ & & & \\
\hline IIP_GR & & $\begin{array}{l}0.06^{*} \\
(2.00)\end{array}$ & $\begin{array}{l}0.07^{* *} \\
(2.40) \\
\end{array}$ & $\begin{array}{l}0.08^{* *} \\
(2.64) \\
\end{array}$ \\
\hline GDP_GR & $\begin{array}{l}0.16^{*} \\
(1.84)\end{array}$ & & & \\
\hline DGR & $\begin{array}{l}0.16^{* *} \\
(2.33)\end{array}$ & $\begin{array}{l}0.21^{* * * *} \\
(8.04)\end{array}$ & $\begin{array}{l}0.21^{* * * *} \\
(8.42)\end{array}$ & $\begin{array}{l}0.25^{* * *} \\
(14.77)\end{array}$ \\
\hline $\mathrm{CPI}$ & $\begin{array}{l}0.29 * * \\
(2.39) \\
\end{array}$ & $\begin{array}{l}0.36^{* * *} \\
(3.306) \\
\end{array}$ & $\begin{array}{l}0.55^{* * *} \\
(5.87)\end{array}$ & $\begin{array}{l}0.60^{* * * *} \\
(8.81)\end{array}$ \\
\hline RRR & $\begin{array}{l}-0.63^{* * *} \\
(-3.13)\end{array}$ & $\begin{array}{l}-0.40^{* *} \\
(-2.71) \\
\end{array}$ & & \\
\hline $\operatorname{RRR}(-2)$ & & & & $\begin{array}{l}-0.12 * * * \\
(-10.30)\end{array}$ \\
\hline $\operatorname{RRR}(-3)$ & & & $\begin{array}{l}-0.10 * * * \\
(-3.95)\end{array}$ & \\
\hline LA & $\begin{array}{l}0.11^{* * *} \\
(2.85)\end{array}$ & $\begin{array}{l}0.084^{* *} \\
(2.50)\end{array}$ & & \\
\hline DUM_CRISES & $\begin{array}{l}-2.03 * * \\
(-2.03)\end{array}$ & & & \\
\hline $\begin{array}{l}\text { DUM_CRISES } \\
(-2)\end{array}$ & & $\begin{array}{l}-2.5^{* *} \\
(-2.08) \\
\end{array}$ & & \\
\hline $\mathrm{MA}(2)$ & & & & $\begin{array}{l}-0.86^{* *} \\
(3.07) \\
\end{array}$ \\
\hline Period & 2009Q1 - 2017Q1 & 2007Q3 - 2017Q1 & 2007Q4 -2017Q1 & 2007Q3-2017Q1 \\
\hline
\end{tabular}

Source: Author.

Note:

** Significant at 1\% level, ** Significant at 5\% level * Significant at 10\% level. The t statistic is in parenthesis. 
Table 8: Diagnostics

\begin{tabular}{|l|l|l|l|l|}
\hline \multicolumn{2}{|c|}{$\mathrm{EQ1}$} & \multicolumn{1}{c|}{$\mathrm{EQ2}$} & \multicolumn{1}{c|}{ EQ4 } \\
\hline $\mathrm{R}^{2}$ & 0.91 & 0.99 & 0.99 & 0.99 \\
\hline Adjusted $\mathrm{R}^{2}$ & 0.89 & 0.98 & 0.98 & 0.98 \\
\hline $\begin{array}{l}\text { DW } \\
\text { statistics }\end{array}$ & 1.60 & 1.78 & 1.55 & 1.65 \\
\hline $\begin{array}{l}\text { LM } \\
\text { test-first lag }\end{array}$ & $\begin{array}{l}1.40 \\
(0.235)\end{array}$ & $\begin{array}{l}0.07 \\
(0.79)\end{array}$ & $\begin{array}{l}1.62 \\
(0.21)\end{array}$ & - \\
\hline Q-statistics & AC at higher lags & AC at higher lags & AC at higher lags & no AC \\
\hline $\begin{array}{l}\text { JB statistics } \\
(0.4)\end{array}$ & $\begin{array}{l}0.08 \\
(0.96)\end{array}$ & $\begin{array}{l}0.29 \\
(0.86)\end{array}$ & $\begin{array}{l}1.81 \\
(0.407)\end{array}$ \\
\hline $\begin{array}{l}\text { Mean value of } \\
\text { residuals }\end{array}$ & 0 & 0 & 0 & 0 \\
\hline $\begin{array}{l}\text { Breusch-Pagan- } \\
\text { Godfrey test }\end{array}$ & $\begin{array}{l}6.75 \\
(0.56)\end{array}$ & $\begin{array}{l}8.68 \\
(0.394)\end{array}$ & $\begin{array}{l}2.70 \\
(0.75)\end{array}$ & $\begin{array}{l}8.12 \\
(0.15)\end{array}$ \\
\hline $\begin{array}{l}\text { The number } \\
\text { of degrees of } \\
\text { freedom }\end{array}$ & 25 & 31 & 33 & 33 \\
\hline
\end{tabular}

Source: Author.

\section{Conclusion}

We analyzed the effects of $B H$ monetary policy in period Q1 2006 - Q2 2017 by applying four different methodologies. The domestic monetary policy cannot influence either the interest rates or the real effective exchange rate $(R E E R)$. Despite this fact, the monetary conditions, from the industrial production point of view, have been improving since 2014, in comparison with the period after the global economic crisis broke out. The improvement of monetary conditions is the proof that the REER, as an automatic monetary policy instrument, can be effective, and that the interest rate channel is partially functioning. The negative remuneration on excess reserves caused negative yields to maturity on short-term public debt, for the first time in $\mathrm{BH}$ monetary policy history. If maturities of public debt of bh entities are higher, the effects of negative remuneration on yields are lower. The differentiated reserve requirement rate (higher on short-term deposits and lower on longterm deposits) yielded to the extension of the banking sector maturity of liabilities. There is a strong negative interdependence between the reserve requirement rate, as an instrument of monetary policy, and credit growth.

The main scientific contribution of the research lies in the exact, empirical, and econometric rejection of the thesis that the $\mathrm{CBBH}$ is "an ordinary exchange office" and that it is not able to conduct autonomous, discretionary and effective monetary and macroprudential policies in the currency board. Decision-makers in BH should be aware of the effects of monetary policy and its instruments and must insist on their further development, as well as on establishing the responsibility of the $\mathrm{CBBH}$ for the economy. Monetary policy 
instruments of the $\mathrm{CBBH}$ can influence both the real and financial variables in the $\mathrm{BH}$ economy.

Building the models (VAR, VECM, SVAR) in order to monitor the effects of $\mathrm{BH}$ monetary policy on real and financial variables are some of the directions for future research of this kind. It would also be interesting to isolate the effects of the BH monetary policy on the yield curve in the Republic of Srpska and explain the differences with respect to the yield curve in the Federation of Bosnia and Herzegovina. A scientific step forward could also be accomplished with an explanation of the credit and deposit multiplication in the monetary regime with negative remuneration on excess reserves. 


\section{References}

1. Žižić, Mileva, Lovrić, Miodrag and Pavličić, Dubravka. (1992). The Methods of Statistical Analysis. Beograd: Contemporary administration.

2. Benazić, Manuel. (2012). Monetary Policy Index for Croatia.Economic Research. Vol. 25, SE 1: 47-64.

3. Calvo A., Guillermo. (1999). Fixed versus Flexible Exchange Rates. University of Maryland. https://drum.lib.umd.edu/bitstream/handle/1903/4295/ciecrp10. pdf?sequence=1 (accessed 20.9.2017).

4. Fleming, John. (1963). Domestic financial policies under fixed and floating exchange rates. IMF Staff Papers, 9,369-379.

5. Helmi, Mohamad.(2011).Modeling Monetary Policy Rules in the MENA Countries: Issues and Evidence. International Journal of Social Sciences and Humanity Studies, Vol 3, No.2. http://www.sobiad.org/eJOURNALS/journal_IJSS/arhieves/2011_2/ mohamad_husam_helmi.pdf (accessed 20.9.2017).

6. Jović, Dragan. (2017). Expansionary monetary policy of $\mathrm{CBBH}$ and primary market yield to maturity in bh entities short-term public debt. Accounting and business finance 09/17: 47-50.

7. Kodra, Oriela. (2010). Estimation of Weights for the Monetary Conditions Index in Albania. Tirana: $4^{\text {th }}$ Annual SEE Economic Research Workshop.

8. Neil, R.Ericsson, Eilev, S. Jansen, Kerbeshian, A. Neva, and Ragnar, Nymoen. (2012). Interpreting a Monetary Conditions Index in economic policy. http://www.bis.org/ publ/confp06i.pdf (accessed 16.08.2017).

9. Obstfeld, Maurice and Rogoff, Kenneth. (1995). "The Mirage of Fixed Exchange Rates", Journal of Economic Perspectives 9 (4), 73-96.

10. Osborne, Jenny-Kinch and Holton, Sarah. (2010). A Discussion of Monetary Condition Index". ESCB, Bilten 01/2010. p.p. 68-80.

11. Rey, Helene. (2015). Dilemma not Trilemma: The Global Financial Cycle and Monetary Policy Independence. NBER Working Paper No. 21162.

12. Shambaugh, C. Jay.(2004). "The Effect of Fixed Exchange Rates on Monetary Policy", Quarterly Journal of Economics 119 (1), 301-352.

13. Svensson, Lars. (1994). "Fixed exchange rates as a means to price stability: What have we learned?", European Economic Review 38 (3-4), 447-468.

14. Taylor, John.(2000). Using Monetary Policy Rules in Emerging Market Economies. Stanford University. https://pdfs.semanticscholar.org/ a729/6bfda8c15865d52955eb37196c5543ea2a18.pdf (accessed 20.9.2017).

15. Vandenbussche, Jérôme, Vogel, Ursula and Detragiache, Enrica.(2012). Macroprudential Policies and Housing Prices-A New Database and Empirical Evidence for Central, Eastern, and Southeastern Europe. WP 12/303.

16. Agency for Statistics of Bosnia and Herzegovina, www.bhas.ba

17. Central Bank of Bosnia and Herzegovina, www.cbbh.ba

18. Federal Banking Agency, www.fba.ba

19. Bank for International Settlements, http://www.bis.org/publ/confp06i.pdf (accessed 16.08.2017).

20. European Central Bank.(2002). Issues related to Monetary Conditions Indices. Monthly Bulletin June. https://ec.europa.eu/info/business-economy-euro/indicators-statistics/ economic-databases/monetary-conditions-index_en (accessed on 15.09.2017.).

21. Hong Kong Monetary Authority. (2010). A Monetary Conditions Index for Hong Kong. Quarterly Bulletin 11. http://www.hkma.gov.hk/media/eng/publication-and-research/ quarterly-bulletin/qb200011/fa02.pdf (accessed 20.09.2017). 